\title{
An Assessment of the Spatial Variability of Greenhouse Gas Emissions from Landfills: A GIS Based Statistical-Numerical Approach
}

\author{
L. A. K. Perera ${ }^{1}$, G. Achari ${ }^{2 *}$ and J. P. A. Hettiaratchi ${ }^{2}$ \\ ${ }^{1}$ Solid Waste Engineer, ARM Group Inc., 1129 West Governor Road, Hershey, PA, USA \\ ${ }^{2}$ Department of Civil Engineering, University of Calgary, 2500, University Drive N.W., Calgary, AB T2N 1N4, Canada
}

\begin{abstract}
Emission of carbon dioxide and methane, two of the most important greenhouse gases, from landfills is a major concern. In this paper, a pseudo 3-D model, incorporating a 2-D geostatistical technique and a 1-D numerical model, was developed to study the spatial variability of the source strength of landfill gas. The 1-D model was used to represent advective, dispersive and reactive transport of landfill gas across the final cover of a landfill. The 1-D model was combined with a 2-D geostatistical technique to consider spatial distribution of landfill gas. The resulting pseudo 3-D model was developed within the ArcInfo GIS platform. Laboratory and field experiments were conducted to obtain data for calibration and verification of the model. The results indicated that the pseudo 3-D statistical-numerical model could be a useful tool to determine the source strength of landfill gas and to identify the location of hotspots beneath a landfill cover. A discussion of field applications and limitations of the model is also included.
\end{abstract}

Keywords: GIS applications, kriging, landfill gas, numerical modeling, source strength, spatial variations, surface emissions

\section{Introduction}

Methane, a greenhouse gas, has 23 times the global warming potential of carbon dioxide over a 100 -year time horizon (IPCC, 2001). Hence, there is considerable interest in controlling methane emissions from anthropogenic sources such as landfills. Landfill gas (LFG) extraction for energy recovery and/or flaring is one of the methods available to control methane emissions from landfills. However, to design an optimized gas extraction system, the source strengths of LFG, including spatial distribution pattern, should be known.

Source strength of a landfill can be predicted from USEPA's LFG generation model or calculated based on data obtained from a LFG pumping test (Emcon Associates, 1980). A network of gas extraction wells can then be designed in a triangular arrangement with a $27 \%$ overlap of radius of influence (ROI) to recover as much LFG as possible (Gardner et al., 1990). The pipe sizes for the LFG collection network are based on the maximum expected source strength during the design period. Usually the source strength peaks soon after the final layer of waste is placed and decrease gradually with time. Due to wide variations in gas generation at different areas of a landfill, installing wells in a uniform triangular grid pattern could be inefficient. This traditional method of gas extraction system design is costly and leads to lower collection efficiency due to spatial variation in LFG generation. There are two ways one can locate high gas strength areas within a landfill: either by conducting intrusive investigations in the field or by developing and using models which can

\footnotetext{
* Corresponding author: gachari@ucalgary.ca
}

capture the physical-chemical processes within a landfill. Mathematical modeling of landfills can be done by using 3-D numerical techniques. These 3-D numerical models require a significant amount of field data, which are difficult to obtain, especially from closed landfills.

In order to keep the numerical modeling aspect simple and yet have the benefit of a 3-D model, we have developed a psuedo 3-D model, which uses a 1-D numerical model in conjunction with kriging interpolation technique to get gas distributions in the other directions. The method presented in this paper involves the use of Geographic Information System (GIS), a geostatistical technique, and a 1-D numerical model to determine the source strength of LFG and to locate "hotspots" within a landfill. The GIS was used to store and analyze spatially varied data, generate the input data for the external numerical model, execute the external model within GIS, store numerical model output files in GIS database, determine source strength based on spatial variations and then graphically represent the results. The GIS acted as an umbrella for the entire model. Kriging, an unbiased geostatistical technique with known minimum variance, was used to interpolate discrete data points into a continuous surface. The 1-D numerical model was used to estimate the source strength and gas emission at a particular location. The resulting psuedo-3D numerical-statistical model was calibrated and verified using data obtained from a laboratory scale experimental setup and a field scale landfill test cell, respectively.

\section{Model Development}

A finite difference 1-D numerical model for advective, 


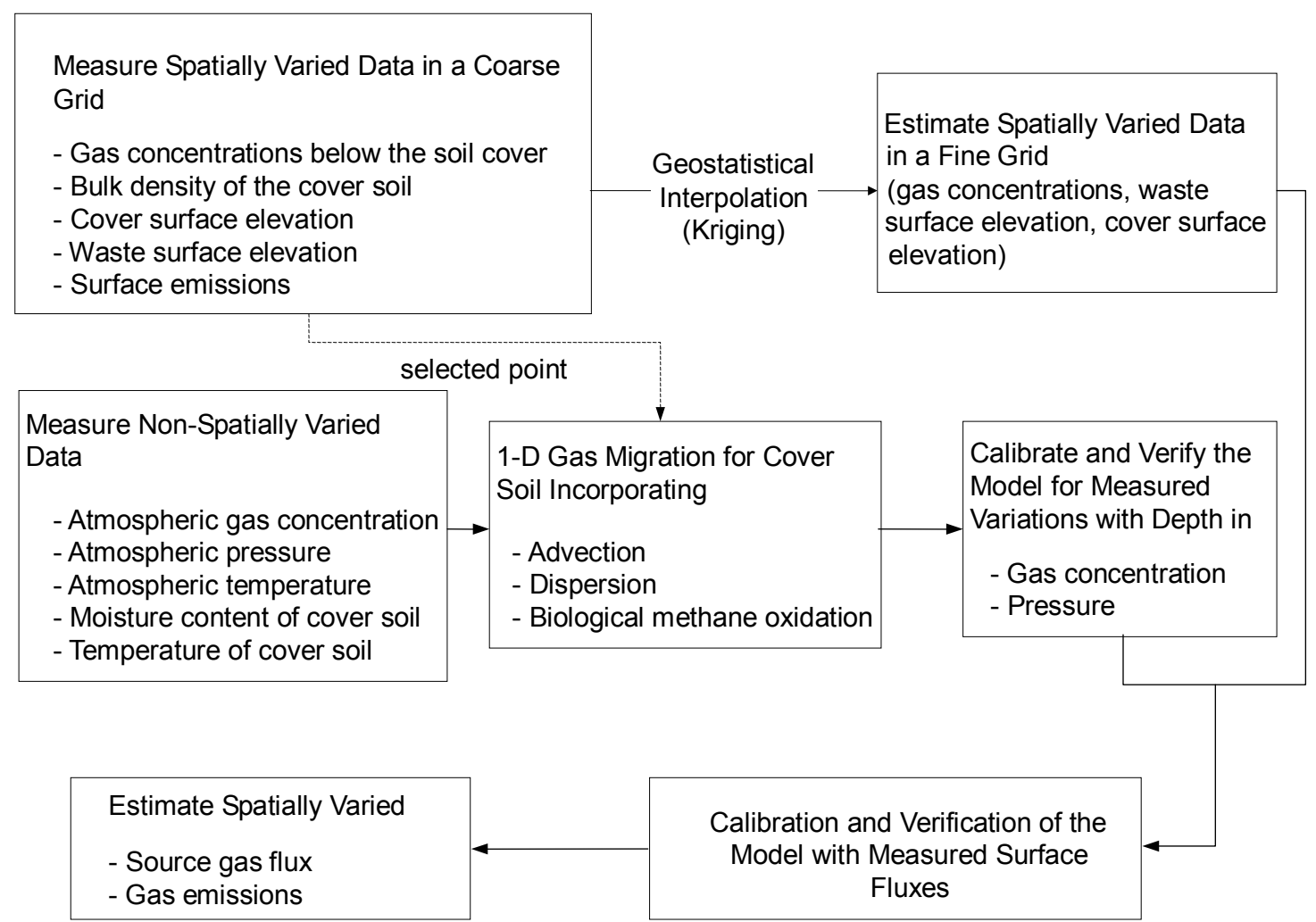

Figure 1. Flow diagram of the pseudo 3-D model.

dispersive, and reactive gas transport through porous media was developed. Then the 1-D numerical model was combined with a 2-D kriging geostatistical model to develop the pseudo 3-D model. A schematic diagram of the modeling process is shown in Figure 1.

The 1-D numerical model included terms for advective and dispersive gas transport in soil and conversion of methane to carbon dioxide by naturally occurring bacteria known as methanotrophs. The mass balance for multi-component gas flow in porous media is given by (Bear, 1972):

$\phi \frac{\partial C_{i}}{\partial t}=-\frac{\partial J_{i}}{\partial x} \pm R_{i}$

where, $i$ refers to any of the four gases (i.e. $\mathrm{CO}_{2}, \mathrm{CH}_{4}, \mathrm{~N}_{2}$ or $\left.\mathrm{O}_{2}\right), \phi=$ air porosity of the medium, $C_{i}=$ concentration of gas i $\left(\mathrm{mol} / \mathrm{m}^{3}\right), J_{i}=$ flux of gas $\mathrm{i}\left(\mathrm{mol} / \mathrm{m}^{2} / \mathrm{sec}\right)$, and $R_{i}=$ generation/consumption rate of gas $i\left(\mathrm{~mol} / \mathrm{m}^{3} / \mathrm{sec}\right)$. The $1-\mathrm{D}$ molar flux of gas component $i$ is given by (Bear, 1972):

$$
J_{i}=v C_{i}+\left(-D_{i, m}^{s} \frac{\partial C_{i}}{\partial x}\right)
$$

where, $v=$ Darcy flux of the gas mixture through the porous medium (m/s), $D_{i, m}^{s}=$ dispersion coefficient of gas $\mathrm{i}$ in a gas mixture in porous medium $\left(\mathrm{m}^{2} / \mathrm{s}\right)$. With these equations and considering a relationship between Darcy flux and pressure, the governing equation for migration of gas $i$ in porous media is given as:

$\phi \frac{\partial C_{i}}{\partial t}=\left(D_{i, \text { mmol }}^{s}+D_{\text {mech }}\right) \frac{\partial^{2} C_{i}}{\partial x^{2}}+\frac{k}{\mu_{m}}\left(\frac{\partial P}{\partial x}\right)\left(\frac{\partial C_{i}}{\partial x}\right) \pm R_{i}$

where, $D_{i, \text { mmol }}^{s}=$ molecular diffusion coefficient of gas i in a gas mixture in the porous medium $\left(\mathrm{m}^{2} / \mathrm{s}\right), D_{\text {mech }}=$ mechanical dispersion coefficient $\left(\mathrm{m}^{2} / \mathrm{s}\right), \mathrm{P}$ is the gas pressure $\left(\mathrm{N} / \mathrm{m}^{2}\right)$ and $\mu_{m}$ is the dynamic viscosity of a mixture of $\mathrm{m}$ gases (Pa·s).

Even though the 1-D model was developed as a transient state model, the model outputs were obtained at steady state. Thus, temporal variations of gas concentrations and other parameters were ignored. This also eliminated the need for considering carbon dioxide partitioning into soil moisture. The parameters of the 1-D model varied with gas composition, temperature and porous media characteristics. The numerical model was solved using partial implicit Crank Nicolson 
method for constant concentration boundary conditions. Details of the 1-D numerical model, its calibration and verification were presented in an earlier paper (Perera et al., 2002a).

A GIS database was developed to store spatially varied data required to execute the calibrated numerical model. These data included: bulk density and moisture content of landfill cover soil, gas concentrations at the waste-cover interface, waste surface elevation, and cover surface elevation. The spatially varied data were stored as attributes to a generated point coverage. Except bulk density, all other variables were analyzed using ordinary kriging (Isaaks and Srivastava, 1989) and contours of these spatial variables were developed. Attempts were also made to krig bulk density but the data did not show any interrelationship amongst neighboring points. Therefore, a grid coverage was created for bulk density. The measured bulk density closest to a grid location was assumed to be valid for the grid.

Separate point coverage was generated to store spatial variables needed to execute the 1-D numerical model. This coverage had a finer resolution than those used to monitor data. Spatially varied discrete data were extracted at grid points from the continuous surfaces and saved as attributes to this point coverage. The numerical model was then executed at each point in the fine resolution coverage to estimate source strength and emission. These were then analyzed to determine the total source strength and total surface emission. "Hotspots", or high source strength areas within the landfill, were identified from the source strength contour maps.

\section{2-D Modeling Using Kriging Interpolation}

Ordinary kriging was used to model gas concentrations at waste-cover interface, waste surface elevations and cover surface elevations in a 2-D horizontal plane. Kriging is a linear and unbiased interpolation technique with a known minimum variance, which allows estimation of regionalized variables, based on discrete data (Isaaks and Srivastava, 1989). Salient features of this technique are discussed below in relation to our application.

In ordinary kriging, a random variable for an unvisited random location $\mathrm{x}_{0}$, is determined from:

$\hat{V}\left(x_{0}\right)=\sum_{i=1}^{n} w_{i} V\left(x_{i}\right)$

where, $\hat{V}\left(x_{0}\right)$ is an estimate of the true value of $V\left(x_{0}\right), \mathrm{w}_{\mathrm{i}}$ is the weight assigned to the observation at location $x_{i}$ and $V\left(x_{i}\right)$ is a random variable at observation location $x_{i}$. In this case, $V$ was the cover surface elevation or the LFG concentration at the waste-cover interface.

We used kriging to determine the sets of weights $\mathrm{w}_{\mathrm{i}}$, which yield an unbiased estimate with minimum variance. For the unbiased condition, the expected value of error should be zero. This can be mathematically expressed as:
$E\left[\sum_{i=1}^{n} w_{i} V\left(x_{i}\right)-V\left(x_{0}\right)\right]=0$

The error variance is given as:

$\tilde{\sigma}_{R}^{2}=\tilde{\sigma}^{2}+\sum_{i=1}^{n} \sum_{j=1}^{n} w_{i} w_{j} \tilde{C}_{i j}-2 \sum_{i=1}^{n} w_{i} \tilde{C}_{i 0}$

where, $\tilde{\sigma}^{2}=$ covariance of random variable at $x_{0}, \tilde{C}_{i, j}=$ covariance between pairs of random variables at $x_{i}$ and $x_{j}$, respectively, $w_{i}$ and $w_{j}=$ weights at locations $x_{i}$ and $x_{j}, \tilde{C}_{i 0}=$ covariance between pairs of random variables at $x_{i}$ and $x_{0}$.

The error variance (Equation 6) was minimized by setting the $\mathrm{n}$ first partial derivatives, with respect to $w_{i}$, to zero. This will result in $\mathrm{n}$ equations with $\mathrm{n}$ unknowns. This, along with Equation (5) gives $n+1$ equations with $n$ unknowns. In order to overcome this redundancy, a Lagrange multiplier is added to Equation (6) and then the two equations were solved to evaluate $w_{i}$. The covariances were found from a mathematical function related to an actual semivariogram, a graph of semivariance and the lag distance. In our experiments, the semivariances were related to a spherical model given by:

$\gamma(h)=b_{0}+b\left(\frac{3 h}{2 a}-\frac{1}{2}\left(\frac{h}{a}\right)^{3}\right) \quad 0 \leq h \leq a$

$\gamma(h)=b_{0}+b \quad h>a$

where $\gamma(h)=$ semivariance, $a=$ range, $h=$ lag distance (distance between two sampling points), $b_{0}=$ nugget variance, and $b_{0}+b=$ sill.

The accuracy of kriged estimates depends on the goodness of fit of the computed semivariogram. In ArcInfo GIS software, the best fit to the actual semivariance points is determined using a non-linear least squares approximation.

Past applications of kriging in landfill situations have produced mixed results. Czepiel et al. (1996a) applied kriging to estimate the total flux from landfill surfaces and found that autocorrelation of data points were apparent at sampling spacings between $0.6 \mathrm{~m}$ and $7 \mathrm{~m}$. The fluxes were estimated using a fitted variogram with combined exponential/Gaussian model. Börjesson et al. (2000) used three different approaches to estimate the total methane emissions from landfill surfaces: kriging on logarithm-transformed data, kriging with extremes excluded, and linear interpolation of measurements. Their results indicated that flux measurements were correlated within a range of $70 \mathrm{~m}$. However, Klusman and Dick (2000) could not find good relationship among neighboring data at 30 $\mathrm{m}$ interval.

\section{Data Storage, Analysis and Display Using GIS}

Unix based ArcInfo 8.0.2 developed by Environmental 
Systems Research Institute was used to store, retrieve, analyze and display geographic data. All the GIS techniques were automated using Arc Macro Language (AML) programs with menu driven operations.

\subsection{Database Development}

The locations of data collection points were stored as point coverage. A boundary map was created to cover all the collected data points using GIS tools. The boundary map was needed for data presentation and geostatistical analysis. The spatially varied data were saved as spreadsheets which were then linked to the point coverage for data collection. As mentioned earlier, kriging geo-statistical interpolation technique was applied to analyze selected data sets. Contour maps were developed using lattice maps generated during kriging. A lattice map is a surface interpretation of a grid represented by equally spaced sample points. Depth of soil cover at different locations were determined from lattice maps for cover surface elevation and waste surface elevation.

\subsection{Preparation of 1-D Model Input Files}

The non-spatially varied data required by the 1-D model such as, atmospheric temperature, atmospheric pressure, atmospheric gas concentration, cover soil temperature and cover soil moisture content were stored as an ASCII file in the database. A rectangular point coverage with nodes created at intersection of perpendicular lines, also known as fishnet (rectangular grid) coverage, was generated at a known resolution to combine all the spatially varied data needed to execute the 1-D model. The selected resolution was finer than those used for data collection but coarser than the resolution used for kriging. The extracted data were saved as a separate ASCII file which could be accessed by the Fortran program for 1-D model.

\subsection{Presentation of Results}

The 1-D model was executed at every point in the fishnet coverage by incorporating spatially and non-spatially varied data to determine source strengths and emissions. These results were then kriged to obtain contours. The source strength at each grid location was multiplied by the grid area and summed to obtain the total source strength. The total emissions were determined using a similar process.

\section{Laboratory Experiments}

Laboratory experiments were conducted to generate data for calibration and verification of the 1-D model and the pseudo 3-D model.

\subsection{Experimental Setup}

Figure 2 illustrates the laboratory experimental unit. The experimental unit had a base area of $0.81 \mathrm{~m}^{2}$, with two compartments. The bottom compartment was divided with aluminum I-sections in a grid pattern to form nine identical sub-compartments. A geotextile layer attached to a filter paper was placed at the middle of each sub-compartment to facilitate distribution of gas within the sub-compartments.

A 3mm thick $0.9 \mathrm{~m} \times 0.9 \mathrm{~m}$ perforated steel plate was placed at the top of bottom compartment resting on the I sections. The steel plate was perforated with $3.2 \mathrm{~mm}$ diameter holes with a center to center spacing of $4.8 \mathrm{~mm}$. The steel plate spanned across all sub-compartments. A rubber seal was placed in between I-sections and steel plate. A fine wire mesh (\# 100) was placed on the steel plate to prevent migration of fines into the bottom compartment. Above the wire mesh, a $2 \mathrm{~cm}$ thick sand layer was placed to homogenize the distribution of the gas at the base. Above the sand layer, $2 \mathrm{~mm}$ sieved soil was filled to a thickness of $0.3 \mathrm{~m}$. Liquid limit and plastic index of the soil were 30 and 11, respectively, indicating the soil to be inorganic clay (CL) (D-2487 ASTM, 1994a). The moisture content of the soil was $9.3 \%$ by weight (D-2216 ASTM, 1994b). The soil was placed in $5 \mathrm{~cm}$ lifts. The soil was tamped using a square wooden tamp of face area $0.09 \mathrm{~m}(\mathrm{~W})$ $\times 0.45 \mathrm{~m}(\mathrm{~L}), 80$ times in 4 rounds, each round was at right angles to the other (C-109 ASTM, 1993). Dry bulk density, determined by dividing the dry weight of the soil by the occupied volume, was $1250 \mathrm{~kg} / \mathrm{m}^{3}$. The particle density of the soil, determined using the method described in Blake and Hartge (1986a), was $2400 \mathrm{~kg} / \mathrm{m}^{3}$.

Carbon dioxide, a non-reactive gas, was fed through the middle sub-compartment through a nozzle fitted at the base at a controlled flow rate. Gas samples were taken at equally spaced four locations within each sub-compartment. At each location, a sampling tube connected to a $6 \mathrm{~mm}$ brass straight union (swagelok) was embedded at mid-depth and full-depth. At the center of the experimental setup, four sampling tubes were inserted to collect data along the depth of the soil. A septum was inserted into the swagelok to collect gas samples for concentration measurements. Pressures at sampling locations were determined by inserting a needle, connected to the digital pressure gauge, through the septum.

\subsection{Gas Concentration and Pressure Determination: Laboratory Experiments}

Since the medium is homogeneous and carbon dioxide is supplied at the center, the gas flow patterns were expected to be symmetrical. Therefore, the concentration and pressure data were not measured at all locations. However, to ensure reliability, data were always obtained from at least two symmetrical locations and compared. Gas concentrations and pressures were measured at varying depths along the center. These data were used for calibration and verification of the 1-D model. Two sets of data obtained for carbon dioxide inflow rates of $57 \mathrm{ml} / \mathrm{min}\left(185 \mathrm{~g} / \mathrm{m}^{2} /\right.$ day) and $20 \mathrm{ml} / \mathrm{min}$ (65 g/ $\mathrm{m}^{2} /$ day) were used for calibration and verification of the model, respectively. These flow rates gave two distinct data sets, and are within flux rates expected in typical landfills. 


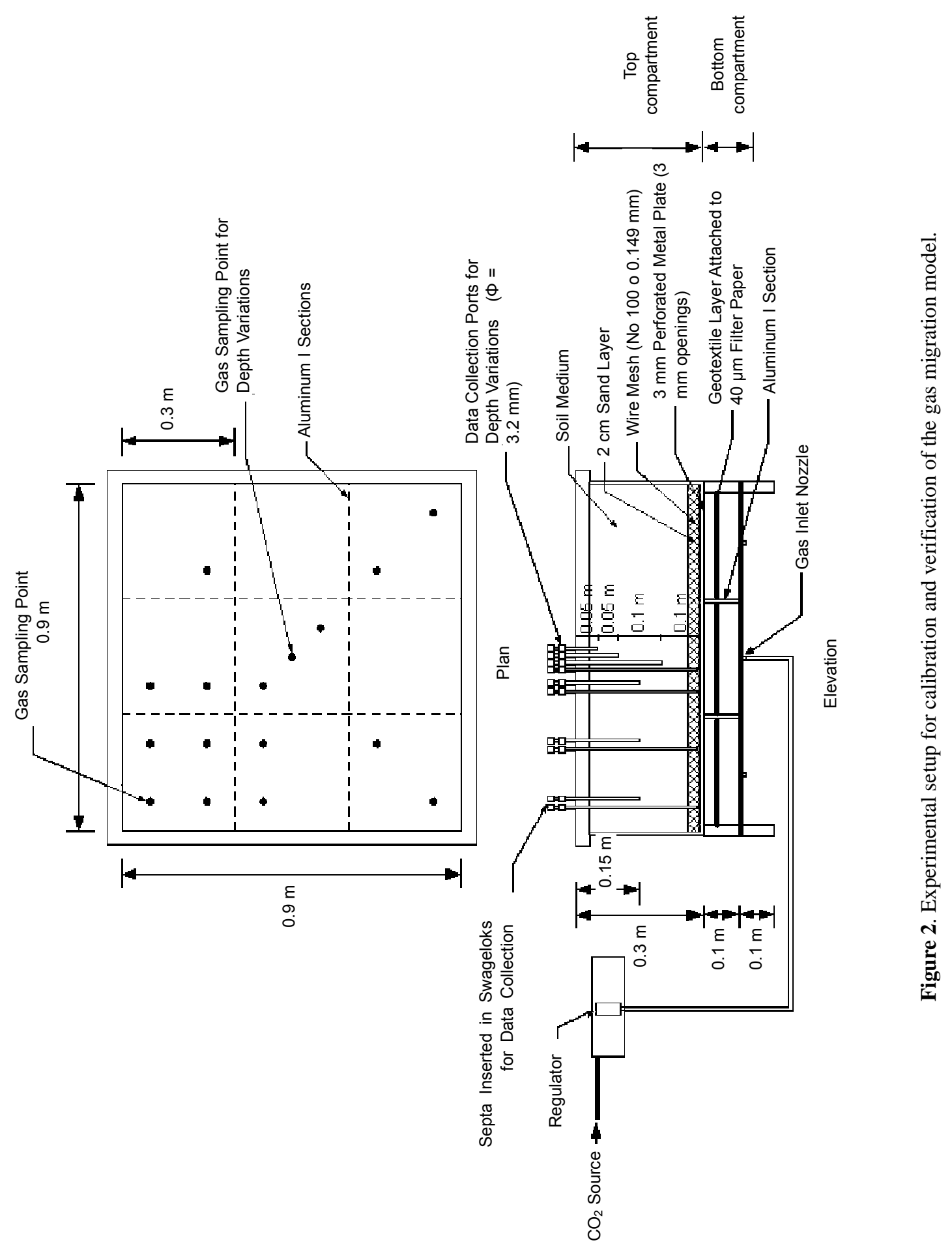




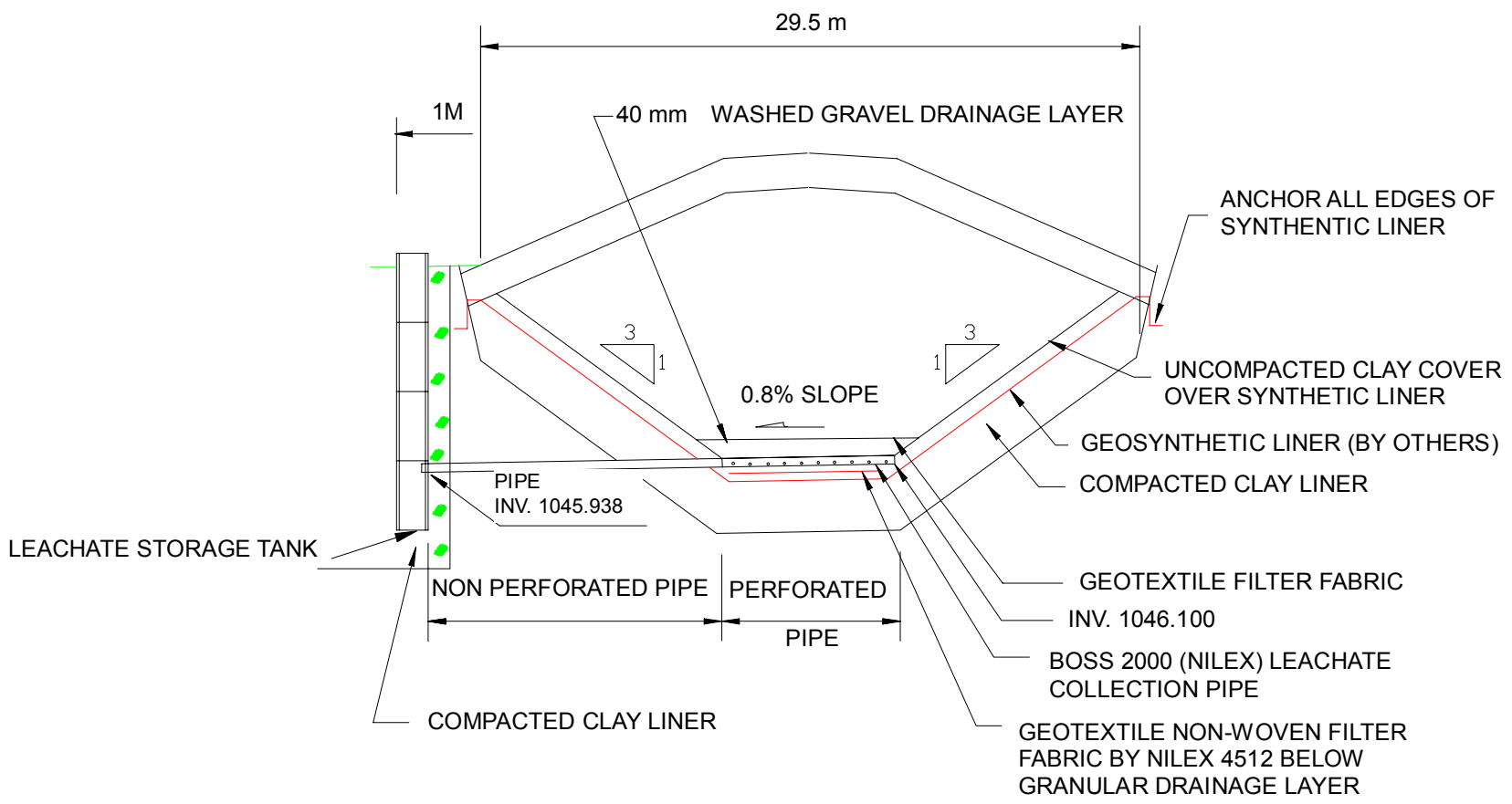

Figure 3. Cross section of the field test cell.

\subsection{Data Collection: Laboratory Experiments}

Carbon dioxide surface flux rates were measured at 36 equally spaced grids on the soil surface using the static flux chamber technique. To ensure symmetry of results, flux measurements from two symmetrical locations were compared and the average value was taken. The flux chamber consisted of a $11 \mathrm{~cm}$ diameter and $3.5 \mathrm{~m}$ high polypropylene container with a septum connected to a swagelok at the center. The open end of the flux chamber was placed on the soil and buried to a depth of $10 \mathrm{~mm}$. Gas samples were extracted using a syringe through the septum in the swagelok and directly injected into a HP P200 micro gas chromatograph (GC) fitted with a thermal conductivity detector. The syringe was purged twice before extracting a sample for analysis. The GC consisted of two columns, A and B. The column A with 5 Angstrom pore size sieve, operated at $60{ }^{\circ} \mathrm{C}$, determined nitrogen and oxygen peaks, whereas the column $\mathrm{B}$, which operated at $35{ }^{\circ} \mathrm{C}$, determined carbon dioxide and methane peaks. The carrier gas was helium. All peaks were quantified using HP EZChrom200 (Anon, 1998) software on a personal computer. At any data collection point, 4 gas samples were extracted at one-minute intervals. The concentration and time plots were non-linear indicating a reduction in gradient with time. This error was caused by the accumulation of carbon dioxide within the flux chamber, which raises the gas pressure and carbon dioxide concentration in the chamber above atmospheric conditions and distorts the gas flow patterns immediately below the flux chamber. The error can be significant due to the small size of the flux chamber (Perera et al., 2002b). To minimize this error, the gradient of the non-linear graph at time zero was used for calculations. The flux was calculated using the method described by Rolston et al. (1978).

Subsurface gas concentrations were determined at the sampling points at full and mid-depth by extracting gas samples and analyzing using the GC. Subsurface gauge pressures were determined using a digital pressure gauge manufactured by The Energy Conservatory, Minneapolis. The pressure readings were always obtained before extracting gas samples for concentration analysis.

\section{Field Scale Landfill Test Cell Experiments}

\subsection{Test Cell Construction and Instrumentation}

A landfill test cell was constructed at the East Calgary landfill in Calgary, Alberta, Canada in June, 1999 to generate data for field verification of the model. Figure 3 provides cross-sectional details of the test cell. The cell dimensions were approximately $29.5 \mathrm{~m}(\mathrm{~W}) \times 37 \mathrm{~m}(\mathrm{~L}) \times 3.75 \mathrm{~m}(\mathrm{D})$ with a base area of $7 \mathrm{~m} \times 7 \mathrm{~m}$. The total air space volume of the test cell was $1815 \mathrm{~m}^{3}$. The side slopes were $3: 1$ at the transverse section and $4: 1$ at the longitudinal section. The slope along the longitudinal section was gentler for compaction 
equipment to move into and out of the test cell during waste filling. The cell base was sloped at $3 \%$ towards the center to facilitate leachate collection. The test cell consisted of a composite bottom liner (i.e. HDPE geo-membrane liner in contact with a compacted clay liner) and a leachate collection system. Once filled with waste, the cell was covered using a thick layer of inorganic clay soil, which was the same soil used in the laboratory experiments. Thickness of cover varied between 0.2 and $0.8 \mathrm{~m}$. The semivariograms obtained for waste surface elevations and cover surface elevations indicated a good interrelationship among neighboring data points.

During filling of the cell, half was filled with commercial waste and the other half was filled with residential waste to obtain a spatial variation in the waste. However, based on a waste composition study conducted by CH2M HILL Canada Limited and visual examination by the City of Calgary employees, it was determined that there was no significant difference between the two waste types. Approximately 50\% of the waste consisted of paper and the rest included yard waste, food waste, plastic, glass and metal. The waste was compacted in layers using a 50 tonne trash compactor. Total quantity of waste in the cell was 1063 tonnes and the average density was $585 \mathrm{~kg} / \mathrm{m}^{3}$. The initial moisture content (by weight) of different waste components was determined using method D2216 (ASTM, 1994b). The moisture content of commercial waste at the time of placement was 33\% whereas for residential waste it was $20 \%$. The cell was left uncovered for a week while filling during which there was some rain. Therefore, it is possible that the water content of the waste may have increased after placement.

At the test cell, the spatially varied data were collected in a rectangular grid pattern (see Figure 4). The dry bulk density of cover soil was measured using the core method (Blake and Hartge, 1986b). Before measuring the bulk density, the topsoil was scraped carefully to a depth of $50 \mathrm{~mm}$ and leveled. Then a $75 \mathrm{~mm}$ diameter annular metal cylinder was driven into the soil to an additional depth of approximately $75 \mathrm{~mm}$ and carefully extracted a known volume of soil, as it existed in-situ. Water content of the sample was determined using the standard method D 2216 (ASTM, 1994b). Dry bulk density, calculated by dividing dry weight of soil by the bulk volume of soil, ranged from 1400 to $1800 \mathrm{~kg} / \mathrm{m}^{3}$.

Swageloks connected to $3 \mathrm{~mm}$ diameter sampling tubes were embedded up to the waste-cover interface to facilitate gas extraction for concentration measurement. A septum was fixed at one end of the swagelok. The gas samples were extracted through the septum using a syringe and were analyzed for carbon dioxide, methane, nitrogen, and oxygen using the portable GC. The syringe was purged twice before extracting a sample for analysis. Gas concentrations were monitored weekly from May to September 2000, and measured daily for three days on three separate occasions during this 4 month period. Gauge pressures at waste-cover interface were measured before extracting gas samples using the digital pressure gauge. The measured pressure was approximately $7 \mathrm{~Pa}$ above atmospheric.

\subsection{Measurement of Gas Concentration at Test Cell}

Carbon dioxide and methane flux rates were measured at selected grid areas on the soil surface using the static flux chamber technique (Rolston et al., 1978). The flux chamber consisted of a $8 \mathrm{~cm}$ high polypropylene container with a diameter of $25 \mathrm{~cm}$. Two swagelok connections were attached to the container to extract gas samples. The open end of the flux chamber was placed on the ground and buried to a depth of $20 \mathrm{~mm}$. Gas samples from the chamber were collected using a syringe and then analyzed using a portable GC. At any flux measurement location, 4 gas samples were extracted at 5 minute intervals. Unlike in the flux measurements during laboratory experiments, in this case, the carbon dioxide concentrations increased linearly with time. The error introduced due to static flux chamber was minimal because a larger flux chamber was used. Three sets of surface flux measurements were obtained in May, July and September of 2000.

The variations in total pressure and gas composition with depth in the soil cover was measured along with surface flux at two selected locations towards the middle of the test cell for calibration and verification of the 1-D model (see Figure 4). A nested sampling probe with three tubes driven to depths of $0.66 \mathrm{~m}, 0.42 \mathrm{~m}$, and $0.17 \mathrm{~m}$ was used to extract gas samples.

\subsection{Measurement of Methanotrophic Activity at Test Cell}

The methanotrophic activity in the cover soil was estimated using batch experiments as described by Czepiel et al. (1996b). Approximately $10 \mathrm{~g}$ of soil were transferred to 240 $\mathrm{ml}$ incubation bottles. The bottles were sealed with teflon-silicone septa. Methane gas was injected into the bottle using a syringe such that the concentration of methane in the headspace was maintained at about 5\% (by volume). Bottle headspace was sampled initially at half hour intervals and then, at 1 hour intervals by extracting $2 \mathrm{ml}$ of gas using a $5 \mathrm{ml}$ syringe. The experiment was continued until sufficient data were obtained to determine the parameter $V_{\max }$. The maximum methane oxidation rate for the soil used in the cover was $6.5 \times$ $10^{-8} \mathrm{~mol} / \mathrm{kg}$ dry soil $/ \mathrm{s}$.

\subsection{Measurement of Moisture Content, Pressure and Tem- perature at Test Cell}

The soil moisture content in the soil cover at a depth of 3 cm was measured using a ThetaProbe manufactured by Delta-T Devices, Cambridge, England. The ThetaProbe responds to the apparent dielectric constant of the fluid. The response changes are converted to a DC voltage proportional to the volumetric soil water content. The moisture content of cover soil varied between $17 \%$ and $31 \%$ (by volume) with an average moisture content of $22 \%$ (by volume). No spatial interrelationship among neighboring moisture data was observed. This could be due to the small area of the test cell. 


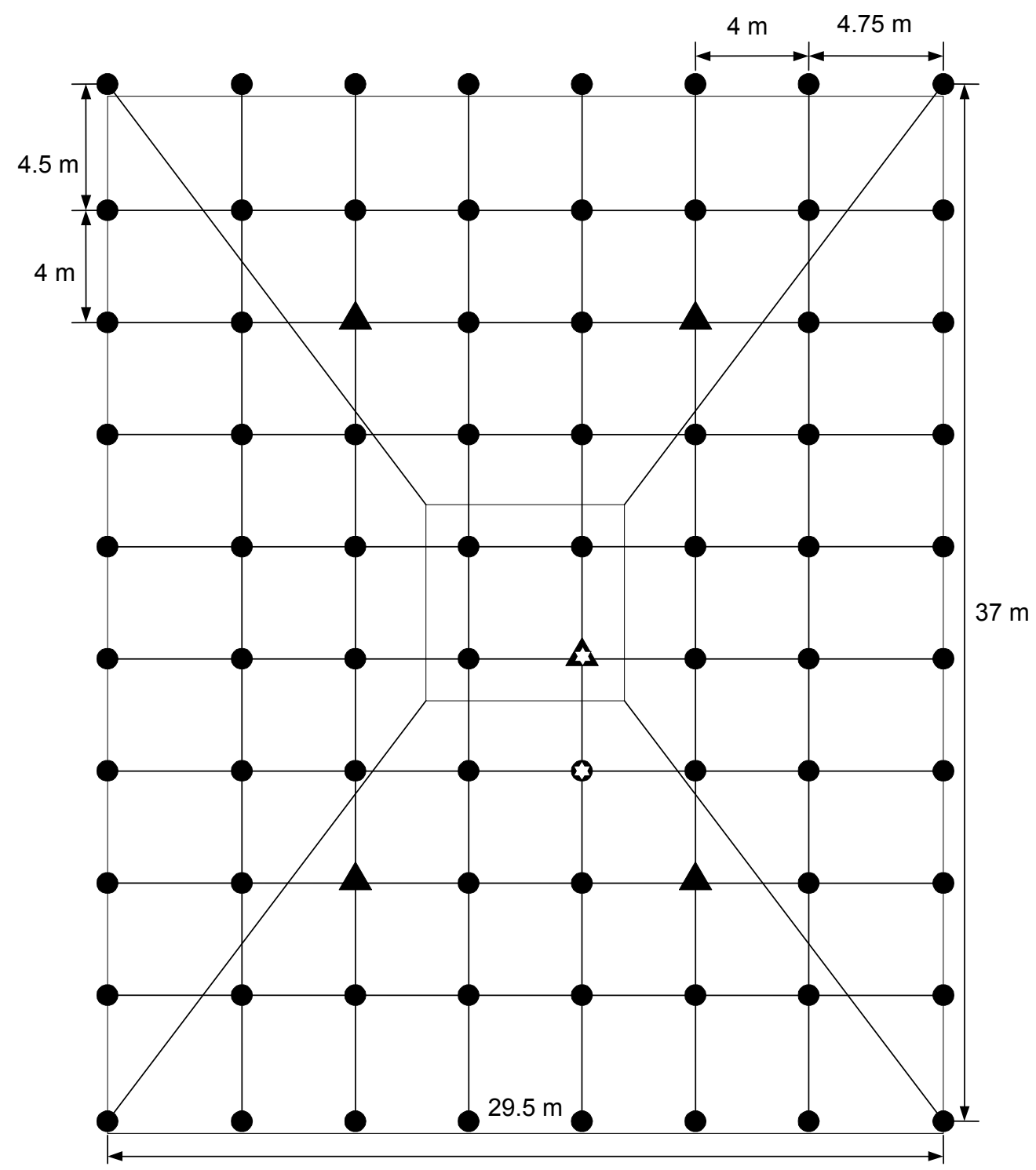

Sampling points for pressure and concentration at the waste cover interface
Sampling points for calibration and verification of 1-D model

- Sampling points for temperature measurement

Figure 4. Sampling pattern.

Atmospheric pressure was measured using a digital barometer. The landfill cover temperature was measured using $\mathrm{T}$ type thermocouples at five selected locations (see Figure 4). The outside four thermocouples were buried to a depth of 25 $\mathrm{cm}$ from the surface whereas the one towards the center of the cell was inserted up to the waste-cover interface $(66 \mathrm{~cm})$. The temperature was directly measured using a Gigi-Sense thermocouple thermometer. The average subsurface temperature was $16.5{ }^{\circ} \mathrm{C}$ while the atmospheric temperature ranged between $16{ }^{\circ} \mathrm{C}$ and $28{ }^{\circ} \mathrm{C}$. The thermocouple readings differed only by $2{ }^{\circ} \mathrm{C}$. No significant variation of subsurface temperature with the cover depth was observed.

\section{Results and Discussion}

\subsection{Laboratory Experimental Results}

7.1.1. 1-D Model Calibration and Verification using Laboratory Data 


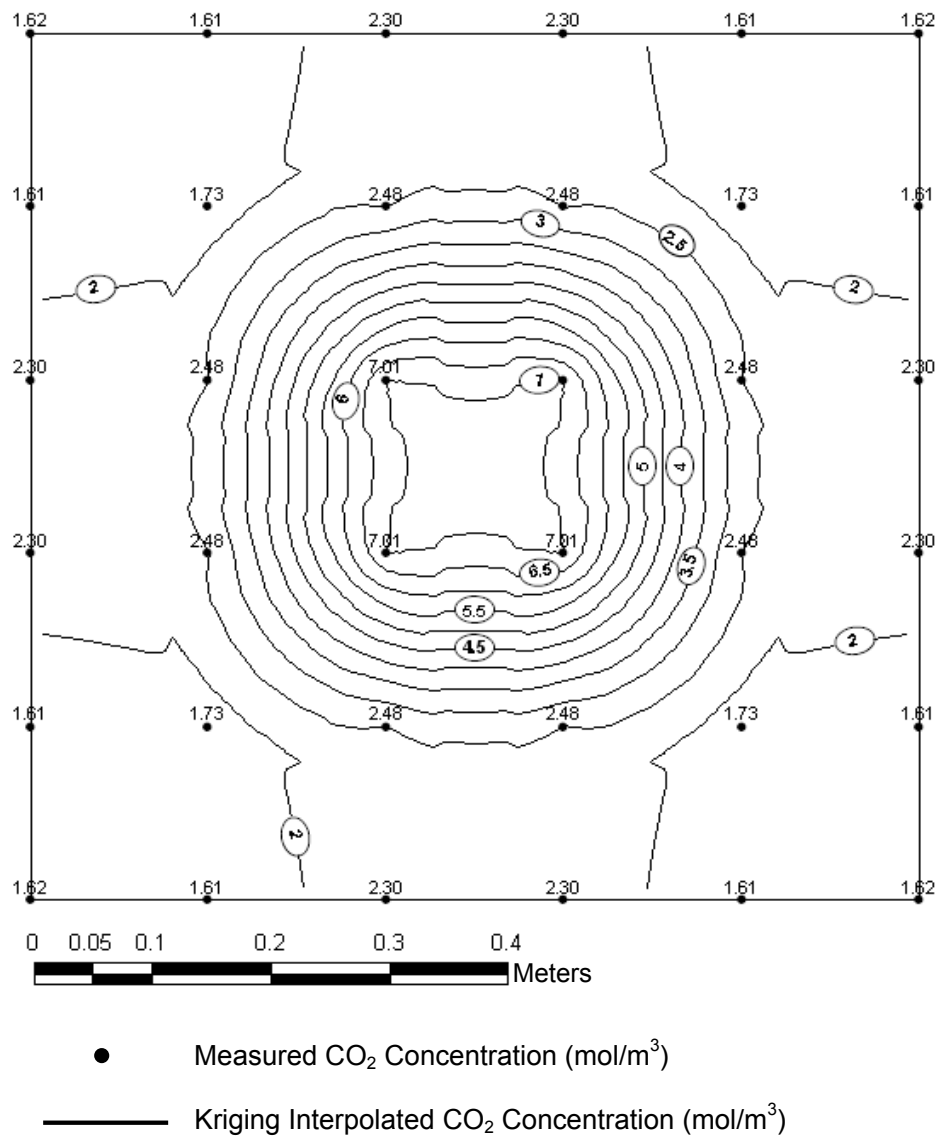

Figure 5. Carbon dioxide concentrations at full depth (inflow $=57 \mathrm{ml} / \mathrm{min}$ ): Laboratory experimental results.

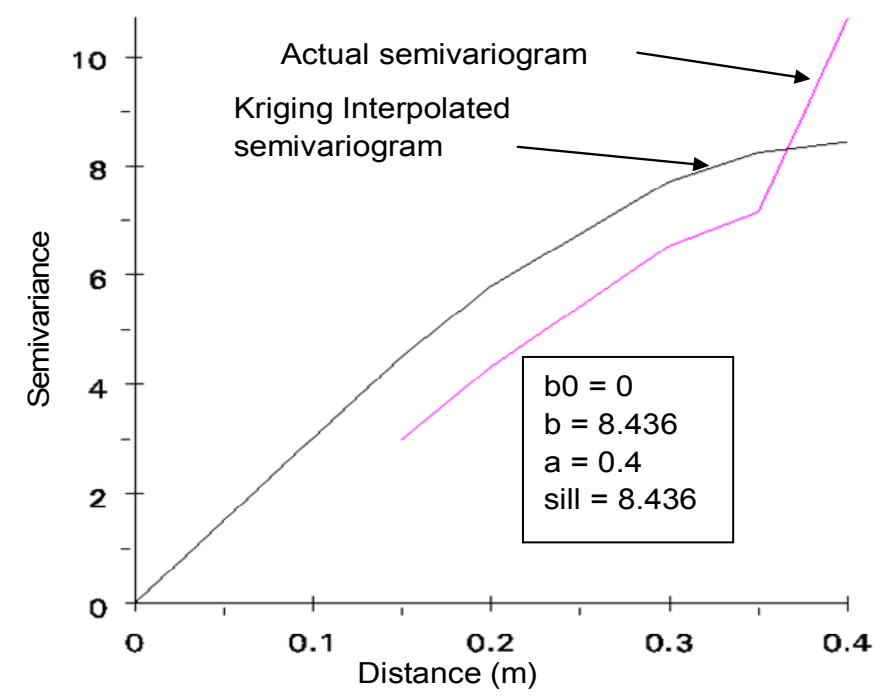

Figure 6. Semivariograms obtained after kriging for carbon dioxide: Laboratory experimental results. 
The data set to calibrate the 1-D numerical model was generated using an input carbon dioxide flow rate of 57 $\mathrm{ml} / \mathrm{min}\left(185 \mathrm{~g} / \mathrm{m}^{2} /\right.$ day $)$. The experimental results indicated a 4 Pa drop through the $0.3 \mathrm{~m}$ depth of soil. The calibration parameters included longitudinal dispersivity, intrinsic permeability and relative diffusion coefficient. These parameters were adjusted manually to match the measured carbon dioxide flux rate with the calculated values at the surface of the soil. At the same time, measured concentrations and pressures were compared with calculated values. The values of calibrated parameters are presented in Table 1 . The calibrated model was verified using a second set of data at an input carbon dioxide flow rate of $20 \mathrm{ml} / \mathrm{min}\left(65 \mathrm{~g} / \mathrm{m}^{2} /\right.$ day). The model calculated carbon dioxide flow rate was over estimated by $6 \%$. It should be noted that this is an estimation based on model input parameters such as gas concentrations at the soil-waste interface and physical properties of the soil medium whereas kriging estimations presented below are based on interpolation of measured and/or predicted data.

Table 1. Laboratory experiments: values of calibrated parameters

\begin{tabular}{ll}
\hline Parameter & Value \\
\hline Intrinsic permeability & $3.0 \times 10^{-12} \mathrm{~m}^{2}$ \\
Relative diffusion coefficient & 0.208 \\
Longitudinal dispersivity & $0.065 \mathrm{~m}$ \\
\hline
\end{tabular}

\subsubsection{Spatially Varied Input Gas Concentrations}

Since the soil layer was homogeneous, the gas concentration at the bottom of the soil layer was the only spatially varied parameter. Figure 5 shows the carbon dioxide concentrations at the bottom of the soil layer measured for an input carbon dioxide flow rate of $57 \mathrm{ml} / \mathrm{min}$. The data were collected at $0.15 \mathrm{~m}$ intervals. Although a highly permeable sand layer was used at the bottom, a high radial concentration gradient was observed. The measured data were used to estimate carbon dioxide concentrations at every $0.01 \mathrm{~m}$ interval using kriging interpolation. The associated contours obtained after kriging are also shown in Figure 5. Similar concentration contours were also prepared for nitrogen and oxygen. Concentration data at every $0.05 \mathrm{~m}$ interval were extracted and used as the bottom boundary condition for the numerical model input.

The semivariogram obtained during kriging for carbon dioxide concentrations is illustrated in Figure 6. A spherical model for the semivariogram was assumed. The coefficients used in the spherical model are shown in the figure. These coefficients were obtained to best fit the actual semivariogram by varying the range. At relatively short lag distances, the semivariance is small, but increases with the distance between the pairs of sample points. Beyond a distance of $0.35 \mathrm{~m}$, the semivariance increased rapidly indicating decreasing correlation between data points. The semivariograms for nitrogen and oxygen also showed that neighboring data points are strongly correlated up to a distance of $0.4 \mathrm{~m}$.

\subsubsection{Mid-depth Carbon Dioxide Concentrations}

Carbon dioxide concentrations at mid-depth were measured and compared with the model calculated carbon dioxide concentrations. The results (see Figure 7) indicate over-estimation of modeled and kriging interpolated carbon dioxide concentration towards the center and under-estimation towards the edges. This could be the result of lateral migration of carbon dioxide at high input flow rates.

\subsubsection{Surface Flux for Carbon Dioxide}

In Figure 8, the surface flux measurements for carbon dioxide were compared with the model calculated surface fluxes. The model results agree with the measured values indicating that the pseudo 3-D model is a reasonable approximation of a real 3-D model. Some lateral migration that may have occurred during migration of carbon dioxide from bottom to top had no significant impact on model results. Since soil properties were homogeneous and there was no carbon dioxide source or sink within the soil, the spatial variations in surface emission were equal to source strength. The model calculated total source strength underestimated the actual source strength of $57 \mathrm{ml} / \mathrm{min}\left(185 \mathrm{~g} / \mathrm{m}^{2} /\right.$ day $)$ by $12 \%$, indicating potential experimental errors.

\subsubsection{Determination of "Hotspots"}

Hotspots in a landfill cell are locations of high source strength and are formed when there is heterogeneity in the waste and the cover. The measured average carbon dioxide source strength was $162.8 \mathrm{~g} / \mathrm{m}^{2} /$ day. The source strength at the center of the experimental setup was higher than average, whereas it was lower at peripheral areas (see Figure 8), indicating that the hotspot for carbon dioxide was at the center. This was expected, since carbon dioxide was sent only from the middle sub-compartment.

\subsection{Field Test Cell Results}

\subsubsection{1-D Model Calibration and Verification using Field} Data

Unlike in the laboratory experiments where carbon dioxide was used, in the field scale experiments there are four calibration parameters. The calibration parameters included longitudinal dispersivity, intrinsic permeability, relative diffusion coefficient, and maximum methane oxidation rate. The values of the 1-D model calibrated parameters are given in Table 2. The data set obtained with no methane at the wastecover interface was used to calibrate for longitudinal dispersivity, intrinsic permeability, and relative diffusion coefficient. The data set with methane at the waste-cover interface was used to calibrate for maximum methane oxidation rate. The calibrated parameters were manually adjusted to match the measured surface flux rate for carbon dioxide. At the test cell, no surface emission of methane was noted. The measured 


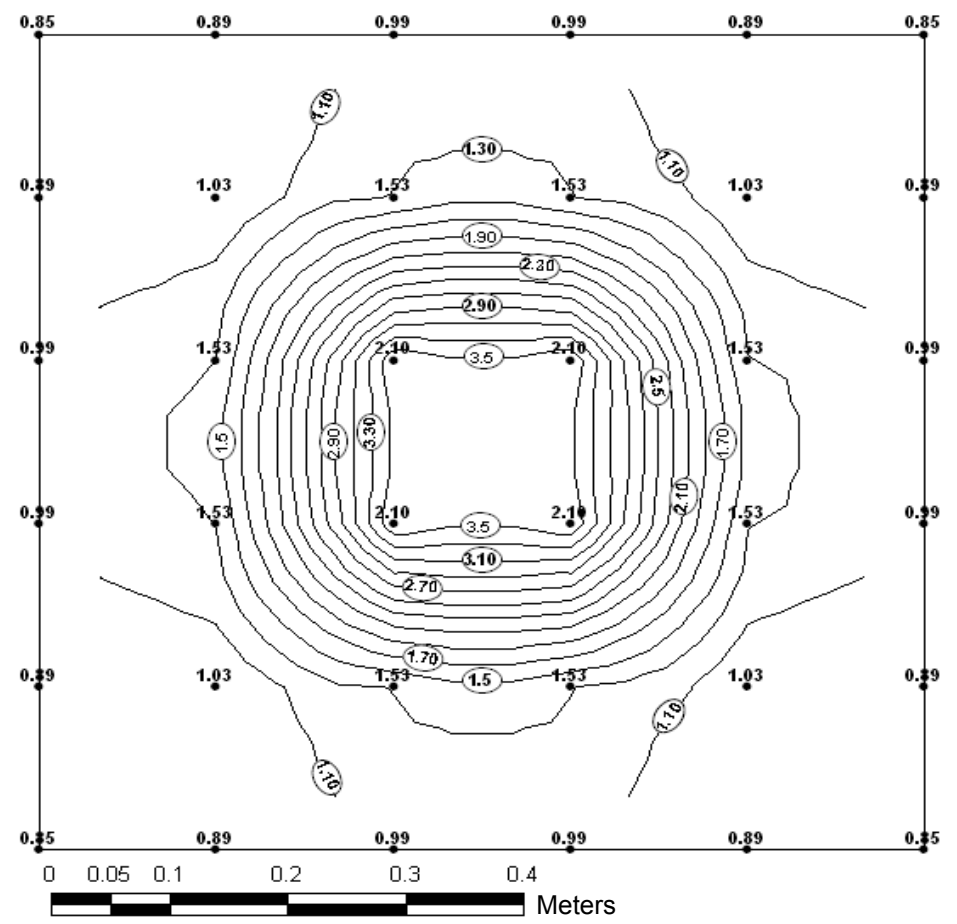

- Measured $\mathrm{CO}_{2}$ Concentration $\left(\mathrm{mol} / \mathrm{m}^{3}\right)$

Modeled and Kriging Interpolated $\mathrm{CO}_{2}$ Concentration $\left(\mathrm{mol} / \mathrm{m}^{3}\right)$

Figure 7. Carbon dioxide concentrations at mid depth (inflow $=57 \mathrm{ml} / \mathrm{min}$ ): Laboratory experimental results.

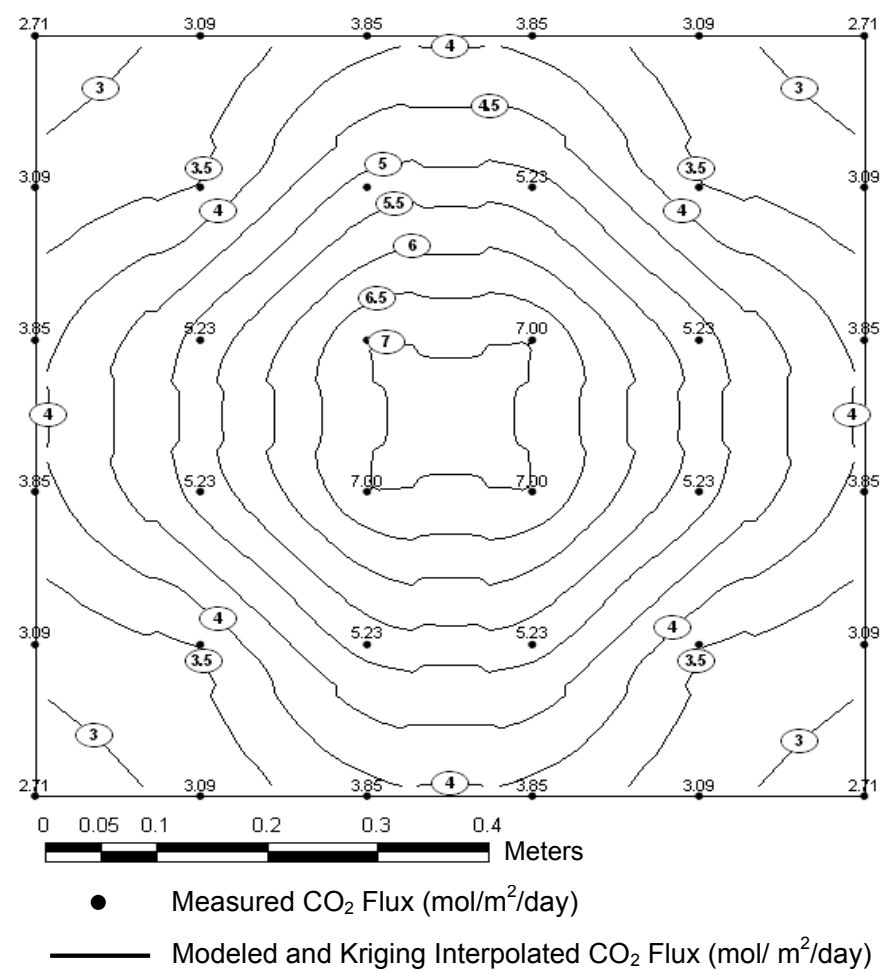

Figure 8. Carbon dioxide surface flux (inflow $=57 \mathrm{ml} / \mathrm{min}$ ): Laboratory experimental results. 


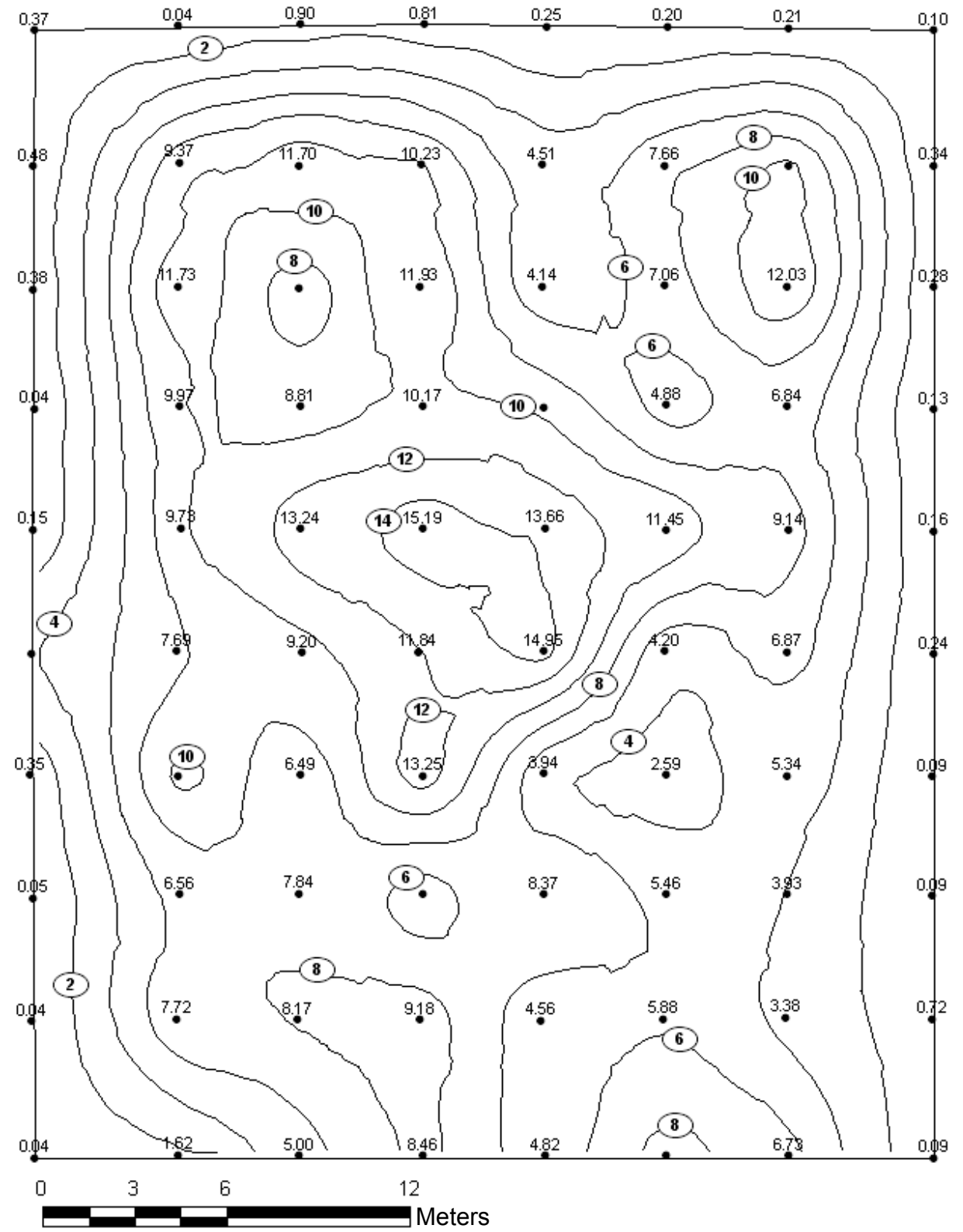

- Measured $\mathrm{CO}_{2}$ Concentration $\left(\mathrm{mol} / \mathrm{m}^{3}\right)$

Kriging Interpolated $\mathrm{CO}_{2}$ Concentration $\left(\mathrm{mol} / \mathrm{m}^{3}\right)$

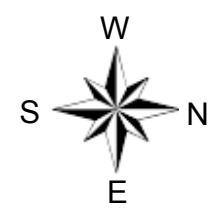

Figure 9. Carbon dioxide concentrations at waste-cover interface: Field data measured in May 2000 and kriging interpolated. 
methane concentrations and pressures at different depths were also compared with model calculated pressures and concentrations. The maximum methane oxidation rate obtained during calibration varied from $6.5 \times 10^{-11}$ at the bottom to 6.5 $\times 10^{-9} \mathrm{~mol} / \mathrm{kg}$ dry soil $/ \mathrm{s}$ at the top. The measured maximum methane oxidation rate for topsoil was $6.5 \times 10^{-8} \mathrm{~mol} / \mathrm{kg}$ dry soil/s. This is one order of magnitude more than the calibrated value. Higher methane oxidation rates in the laboratory experiments could be the result of higher temperatures in the laboratory $\left(21^{\circ} \mathrm{C}\right)$ compared to field $\left(16{ }^{\circ} \mathrm{C}\right)$ as well as higher oxygen availability. The longitudinal dispersivity was set to zero due to negligible advective transport.

Table 2. Field experiments: values of calibrated parameters

\begin{tabular}{ll}
\hline Parameter & Value \\
\hline Intrinsic permeability & $1.0 \times 10^{-13} \mathrm{~m}^{2}$ \\
Relative diffusion coefficient & 0.013 \\
Longitudinal dispersivity & 0.0 \\
Maximum methane consumption rate & $6.5 \times 10^{-11}-6.5 \times 10^{-9}$ \\
& $\mathrm{~mol} / \mathrm{kg} \mathrm{dry} \mathrm{soil} / \mathrm{s}$ \\
\hline
\end{tabular}

The model was then verified using a second set of data obtained on a different date. The measured carbon dioxide concentration and pressure variations with the depth were in agreement with modeled data. However, the modeled and kriging interpolated carbon dioxide surface fluxes were underestimated by $15 \%$. The change in intrinsic permeability due to moisture content could be a reason for the deviation. The measured volumetric moisture content in the second set of data was $22 \%$, whereas in the first set of data, it was $25 \%$. The decrease in moisture content in the second set should actually increase the air permeability. This could be a reason for underestimation.

\subsubsection{Spatially Varied Input Gas Concentrations}

Figure 9 shows the spatially varied carbon dioxide concentrations measured at the waste-cover interface. The measured data were used to estimate carbon dioxide concentrations at every $0.25 \mathrm{~m}$ interval using kriging interpolation. The contour map obtained with kriged data is also shown in the Figure 9. The kriging-interpolated data are in agreement with the measured data. A high carbon dioxide concentration was observed towards the center of the test cell. Higher depth of waste at the center, resulting in a high gas production, may have contributed to this observation. The semivariogram obtained after kriging interpolation is shown in Figure 10. The coefficients used in the spherical model are given in the figure. This semivariogram does not appear to give a good relationship among neighboring data points. However, according to the best-fit curve, the neighboring points are related within a range of $13 \mathrm{~m}$. Lack of spatial relationship could be due to carbon dioxide being generated in isolated pockets. Following the same procedure, contour maps were developed for the other three major gases (i.e. methane, nitrogen, and oxygen). The concentration data at every $1 \mathrm{~m}$ interval were extracted for each gas and were used as a boundary condition for the numerical model.

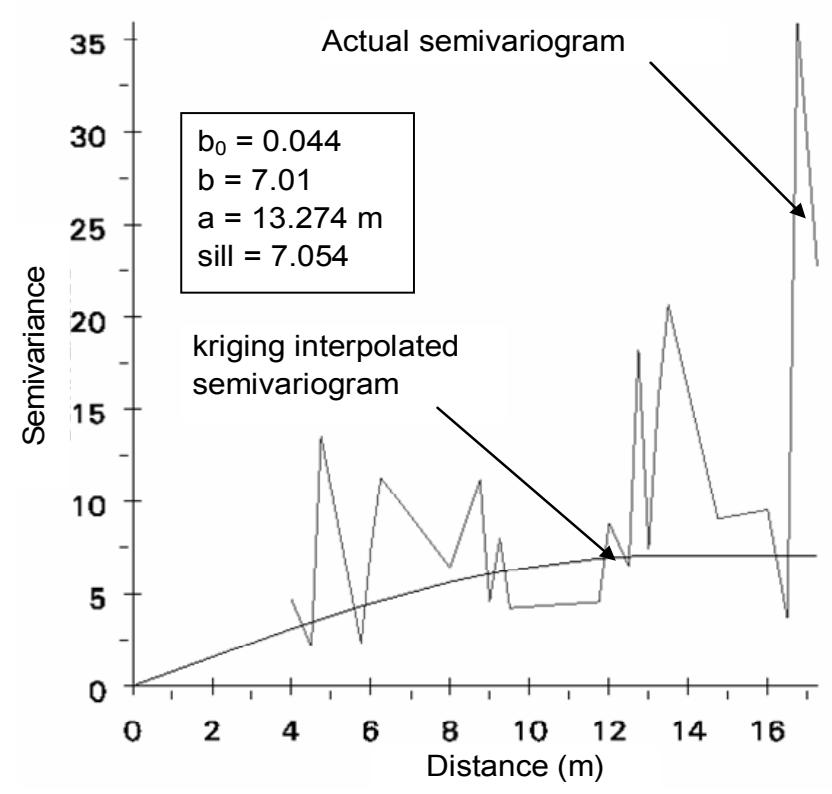

Figure 10. Semivariogram for carbon dioxide: Measured

Field Data.

\subsubsection{Surface Flux of Gases}

Figure 11 shows the measured and, modeled and kriging interpolated carbon dioxide surface fluxes for the data set obtained on May 15, 2000. In order to match the measured flux data, the dry bulk density of the cover soil was adjusted at some locations during calibration of the spatially varied model. As the bulk density measurements were made at $5 \mathrm{~cm}$ below the surface of the cover and changes in bulk density with the depth of the cover were neglected, some errors may have been introduced. The model was then applied to two sets of data obtained on July 18, 2000 and September 22, 2000 to verify the surface flux measurements. However, only July 2000 results are presented in this paper.

Since landfills are slowly changing environments, significant changes over a short period of time will not occur unless there are environmental changes such as precipitation. The results are shown in Figure 12 for measured, modeled, and kriging-interpolated flux data. The presence of a number of hotspots is evident. It also clearly shows the spatial variability of gas flux.

\subsubsection{Source Strength of Gases}

Figures 13 and 14 illustrate the spatial variation of source strengths of carbon dioxide and methane for data collected in May 2000. The total source strength of carbon dioxide was $238 \mathrm{~mol} /$ day, whereas total source strength of methane was 25 $\mathrm{mol} / \mathrm{day}$. On the other hand, the total emission of carbon dioxide and methane into the atmosphere was $255 \mathrm{~mol} /$ day 


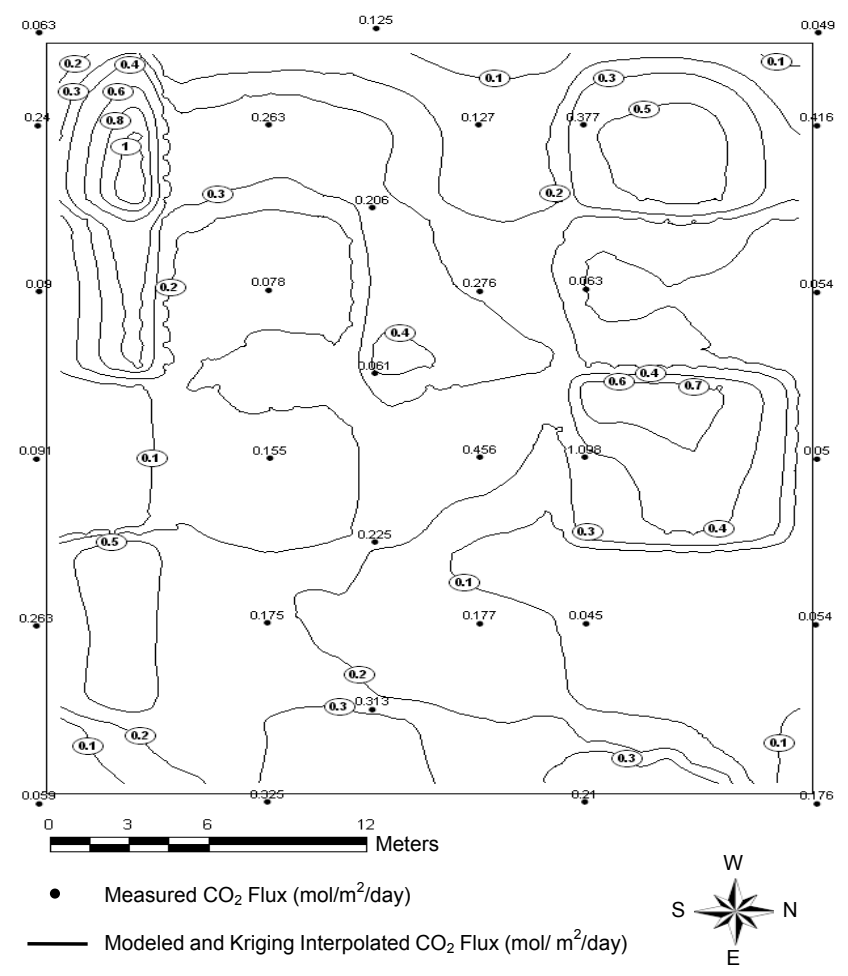

Figure 11. Carbon dioxide surface flux: Field data measured in May 2000 and, modeled and kriging interpolated.

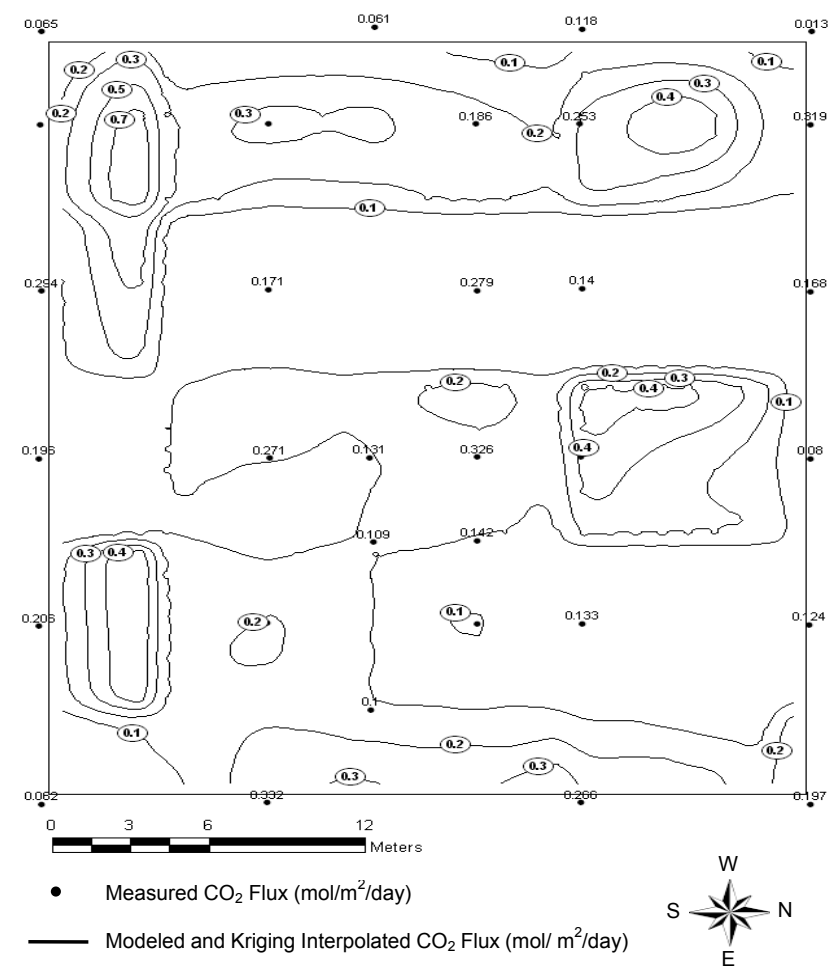

Figure 12. Carbon dioxide surface flux: Field data measured in July 2000 and, modeled and kriging interpolated. 
and $0.3 \mathrm{~mol} / \mathrm{day}$, respectively. The higher observed surface flux of carbon dioxide emission was the result of oxidation of methane by the methanotrophic bacteria present in the soil. Source strength obtained for the test cell was much less than the total LFG generation rates of $15-60 \mathrm{~m}^{3} /$ tonne of wastes/year re ported by Ham and Barlaz (1989) during active methane generation in a typical landfill. Low waste degradation rates may be due to a number of reasons; low moisture content at waste placement, presence of slower biodegradable material, cold temperatures and semiarid climatic conditions in the Calgary area. No experiments have been conducted to confirm any of these facts. From Figure 13, four carbon dioxide hotspots can be identified. High methane hot spots were identified at the east side and towards the center of the test cell (see Figure 14).

\section{Model Strengths and Limitations}

The pseudo 3-D model outputs include spatially varied source strength and surface flux rates of methane and carbon dioxide. By summing the spatially varied source strengths, the total source strength can be obtained. Since atmospheric pressure is used as an input to the model, the effect of changing atmospheric pressure on gas migration within the cover can be determined.

During model development, it was assumed that there was no lateral migration of gas from the landfill into the surrounding soil. This is true for a landfill cell with a low permeable bottom liner. The model has been calibrated and verified for constant concentration boundaries assuming quasi steady state conditions. It has been assumed that rapid changes in the concentration of gas at the source (i.e. at waste-cover interface) did not occur. The field experiments also indicated no rapid changes in concentrations at the waste-cover interface. The model predicts gas source strength immediately below the cover.

Soil respiration was not considered in the model development. Under our test conditions (both laboratory and field), soil respiration effects were low due to low organic content of the soil. This was confirmed by the relatively low methane oxidation rates $\left(6.5 \times 10^{-8} \mathrm{~mol} / \mathrm{kg}\right.$ dry soil/s) obtained for this soil. However, if there is considerable amount of soil respiration, then carbon dioxide generation and oxygen utilization due to soil respiration should be included in the 1-D numerical model.

If sufficient oxygen is available within the top few meters, methane oxidation will occur within the landfilled waste itself, because of naturally occurring methanotrophic bacteria. Oxidation of methane within the landfilled waste was not considered in the model.

Another assumption used in the pseudo 3-D model is that there are no variations with depth of physical parameters, such as bulk density, moisture content, subsurface temperature, and intrinsic permeability. Further, it was assumed that there were no spatial variations of the 1-D model calibration parameters.

\section{Conclusions}

A pseudo 3-D model to determine source strengths of various components of LFG and to identify "hotspots" in a landfill was developed. The model combines a 1-D numerical model and geostatistical model to determine the spatial variation of gas source strength and migration. The 1-D model was calibrated and verified for concentration and pressure variation with depth along with surface flux measurements.

This paper demonstrates the potential of using GIS (kriging) in combination with a 1-D numerical model to locate hotspots at the waste-cover interface. Contour maps developed for spatially varied gas concentrations and fluxes were also in agreement with measured data. At the current stage of development, the model can be used in landfills with cover soils where $\mathrm{CO}_{2}$ production is limited.

Acknowledgments. This research is supported by the NSERC, the University of Calgary, the City of Calgary, Alberta Environment and the Nilex Corporation. The authors wish to thank the City of Calgary engineers for their help in the design and construction of the test cells, and the staff at East Calgary Landfill for maintenance of the test cells.

\section{References}

Anon (1998). User's Manual. Hewlett-Packard Company, 2850, Centerville Road, Wilmington, DE19808-1610, USA.

ASTM (1993). Standard Test Method for Compressive Strength of Hydraulic Cement Mortars, C109-93, Philadelphia, USA.

ASTM (1994a). Standard Classification of Soils for Engineering Purposes (Unified Soil Classification System), D2487-94, Philadelphia, USA.

ASTM (1994b). Standard Test Method Laboratory Determination of Water (Moisture) Content of Soil and Rock, D2216-94, Philadelphia, USA.

Blake, G.R. and Hartge, K.H. (1986a). Particle density, in A. Klute (Ed.), Methods of Soil Analysis (Part 1), American society of Agronomy Inc., Soil Science Society of America Inc., Wisconsin, pp. 377-381.

Blake, G.R. and Hartge, K.H. (1986b). Bulk density, in A. Klute (Ed.), Methods of Soil Analysis (Part 1), American society of Agronomy Inc., Soil Science Society of America Inc., Wisconsin, pp. 363-375.

Börjesson, G., Danielsson, A.S.A. and Svensson, B.H. (2000). Methane fluxes from a Swedish landfill determined by geostatistical treatment of static chamber measurements. Environ. Sci. Technol., 34(18), 4044-4050.

Conant, R.T., Klopatek, J.M. and Klopatek, C.C. (2000). Environmental factors controlling soil respiration in three semiarid ecosystems. Soil Sci. Soc. Am. J., 64, 383-390.

Czepiel, P.M., Mosher, B., Harriss, R.C., Shorter, J.H., McManus, J.B., Kolb, C.E., Allwine, E. and Lamb, B.K. (1996a). Landfill methane emission measured by enclosure and atmospheric tracer methods. J. Geophys. Res., 101(D11), 16711-16719.

Czepiel, P.M., Mosher, B., Crill, P.M. and Harriss, R.C. (1996b). Quantifying the effect of oxidation on landfill methane emissions. J. Geophys. Res., 101(D11), 16721-16729.

Emcon Associates (1980). Methane Generation and Recovery from Landfills, Ann Arbor Science Publishers Inc., P.O. Box 1425, Michigan, USA.

Gardner, N., Manley, B.J.W. and Probert, S.D. (1990). Design 


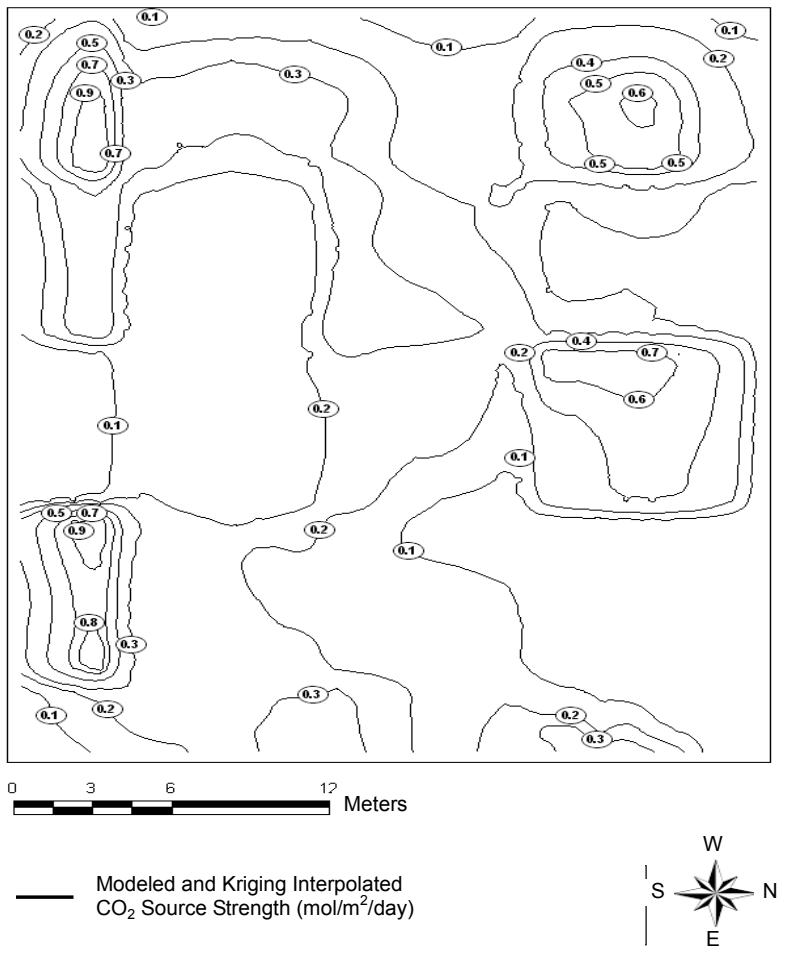

Figure 13. Source strength of carbon dioxide: Field data measured in May 2000 and, modeled and kriging interpolated.

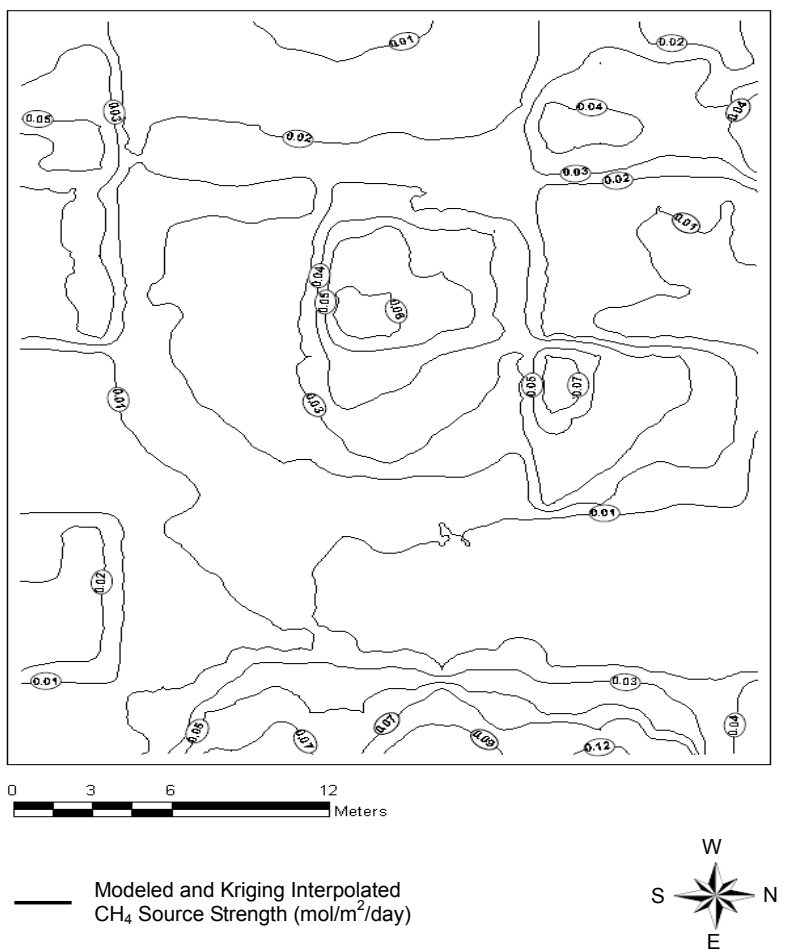

Figure 14. Source strength of methane: Field data measured in May 2000 and, modeled and kriging interpolated. 
considerations for landfill gas producing sites. Appl. Energy, 37, 99-109.

Gunaratne, D.G.M. (2002). Quantification of Landfill Gas Emissions, Unpublished M.Sc. Dissertation, Department of Civil Engineering, University of Calgary, Calgary, Alberta.

Ham, R.K. and Barlaz, M.A. (1989). Measurement and prediction of landfill gas quality and quantity, in T.H. Christensen, R. Cossu and R. Stegmann (Eds.), Sanitary Landfilling: Process, Technology and Environmental Impact, Academic Press, London, UK, pp. 155-166.

Isaaks, E.H. and Srivastava, R.M. (1989). An Introduction to Aapplied Geostatistics, Oxford University Press, New York.

IPCC (2001). Climate Change 2001: The Scientific Basis, J.T. Houghton, L.G. Meira Filho, B.A. Callander, N. Harris, A. Kattenberg and K. Maskell (Eds.), University Press, Cambridge, UK, pp. 944.

Kightley, D., Nedwell, D.B. and Cooper, M. (1995). Capacity for methane oxidation in landfill cover soils measured in laboratory-scale soil microcosms. Appl. Environ. Microbiol., 61(2), 592-601.
Klusman, R.W. and Dick, C.J. (2000). Seasonal variability in methane emissions from a landfill in a cool, semiarid climate. J. Air Waste Manage. Assoc., 50, 1632-1636.

Nozhevnikova, A.N., Lifshits, A.B., Lebedev, V.S. and Zavarzin, G.A. (1993). Emission of methane into atmosphere from landfills in the former USSR. Chemosphere, 26(1-4), 401-417.

Perera, L.A.K., Achari, G. and Hettiaratchi, J.P.A. (2002). Determination of source strength of landfill gas: A numerical modeling approach. J. Environ. Eng., 128(5), 461-471.

Perera, M.D.N., Hettiaratchi, J.P.A. and Achari, G. (2002). An evaluation of closed flux chamber technique for measuring gas emissions from landfills: Model calibration, verification and prediction. J. Environ. Eng. Sci., 1(6), 451-463.

Price, T.J., Probert, S.D. and Manley, B.J.W. (1998). Improving reliability of LFG generation assessment tests. Appl. Energy, 60, 41-63.

Rolston, D.E., Hoffman, D.L. and Toy, D.W. (1978). Field measurement of denitrification: I. flux of $\mathrm{N}_{2}$ and $\mathrm{N}_{2} \mathrm{O}$. Soil Sci. Soc. Am. J., 42, 863-869. 